\title{
A failed repair of a type 1 anterior cruciate ligament tear: Case presentation
}

\author{
Courtney A Quinn ${ }^{1 *}$, Anthony Ignozzi ${ }^{2}$ and Mark D Miller ${ }^{1}$ \\ ${ }^{1}$ Department of Orthopaedic Surgery, University of Virginia, Charlottesville, Virginia, USA \\ ${ }^{2}$ University of Virginia School of Medicine, Charlottesville, Virginia, USA
}

\begin{abstract}
Anterior cruciate ligament (ACL) repair has experienced a resurgence of interest in the last twenty years as our understanding of the healing potential of the ACL has evolved. Sherman Type 1 (proximal avulsion) tears have shown the greatest ability to heal after primary repair. However, there remains insufficient evidence that long term outcomes after ACL repair of type 1 tears are equivalent to or better than the gold standard of ACL reconstruction. In this case presentation, we describe a 17-year-old patient who underwent ACL repair after sustaining a type $1 \mathrm{ACL}$ proximal avulsion who eventually went on to atraumatic failure. We will briefly review the history of ACL repair as well as the current literature and developments.
\end{abstract}

\section{Introduction}

Anterior cruciate ligament (ACL) repair was first described in the late 19th century but became popularized in the 1970's and 1980's as a way to restore native knee biomechanics [1]. Although initial interest in ACL repair was high, the technique fell out of favor as long-term studies showed high rates of graft failure (15-53\%) and reoperations, with ACL reconstruction becoming the standard of care for ACL injuries into the 1990's and beyond [2-5].

Despite this paradigm shift, further analysis of ACL repair, notably by Sherman, et al. identified that the location of the ACL tear played a significant role in the success of primary repair, with improved outcomes seen in patients with true soft-tissue avulsions from the femoral insertion (Type 1 proximal avulsion tears) [6]. Studies on ACL repair in this strict population have reported promising results that have sparked a renewed interest in primary repair $[7,8]$. Importantly, surgical technique has changed drastically in the last 30 years, with vast improvements in arthroscopic techniques, including suture augmentation and biologic scaffolding during ACL repair $[9,10]$. While short- and mid-term outcomes are-again-promising, there is concern in the surgical community that repair is suboptimal compared to reconstruction in the long-term [11]. In this article, we present a case of a failed ACL repair that contributes to the ongoing discussion regarding treatment of Type 1 proximal avulsion tears.

\section{Case Presentation}

The patient is a skeletally mature 17-year-old female that presented with right knee pain after a non-contact cutting injury sustained while playing soccer. An MRI of the right knee revealed a complete ACL tear that appeared to be a proximal avulsion, without other concomitant intra- or extra-articular pathology (Figure 1). Intra-operative evaluation confirmed the femoral-sided avulsion of the ACL (Figure 2). The ligament tissue quality was robust and had the appropriate length and excursion to be reapproximated to the femoral footprint without laxity or undue tension, so it was determined that this tear was amenable to repair. The repair was performed by passing two No. 2 non-absorbable sutures through the proximal ACL stump in luggage-tag fashion, one in the anteromedial bundle, and the other through the posterolateral bundle. These suture ends were then passed through two transosseous tunnels made in their respective bundle attachments of the femoral footprint, exiting the lateral femoral cortex. The repair sutures were fixed on the femoral side with a Hewson Ligament Button (Smith and Nephew) on the lateral cortex. This repair was augmented with a singular 2mm FiberTape (Arthrex, Inc), fixed through separate femoral and tibial tunnels with a PushLock anchor on the femoral side, and a SwiveLock anchor on the tibial anterior cortex (Arthrex, Inc). The ACL was found to have appropriate tension throughout range of motion and post-fixation exam demonstrated excellent stability to Lachman and pivot shift tests (Figure 3).

The patient progressed well through the standard physical therapy rehabilitation protocol. Six-weeks post-operatively, her right knee stability was excellent, range of motion was appropriate, and weightbearing status was full. At the 12-week follow-up, she presented with equivocal side-to side KT-1000 measurements of $3 \mathrm{~mm}$ translation on her operative knee, and $4 \mathrm{~mm}$ on the contralateral. She returned to full sport and activity at 8 months.

The patient then presented 3 years later at the age of 21 to our office with symptoms of right knee pain and the sensation of instability that developed insidiously over 4 months without an identifiable traumatic episode to the knee. She no longer played team sports but was a recreational runner. Physical exam of right knee was remarkable for a trace effusion, positive pivot shift test, and an equivocal Lachman exam. Repeat MRI of the right knee demonstrated a re-tear of the proximal ACL. After a discussion of conservative and surgical options with the patient, she elected to proceed with ACL reconstruction.

*Correspondence to: Courtney Quinn, Department of Orthopaedic Surgery, University of Virginia, 400 Ray C. Hunt Drive, Suite 300, Charlottesville, Virginia, USA, E-mail: courtneyaq@gmail.com

Received: December 10, 2020; Accepted: December 28, 2020; Published: December 31, 2020 
Arthroscopic evaluation demonstrated that the ACL had re-torn from the femoral insertion, although there were some remaining attenuated fibers of the posterolateral bundle. The FiberTape augmentation had failed; remaining suture material was seen attached to the femoral insertion (Figure 4). There was also a small radial tear of the lateral meniscus body, which extended only through the whitewhite zone. This tear was treated with partial meniscectomy. The remaining ACL was debrided, and the ligament reconstructed using a bone-patellar tendon-bone autograft.

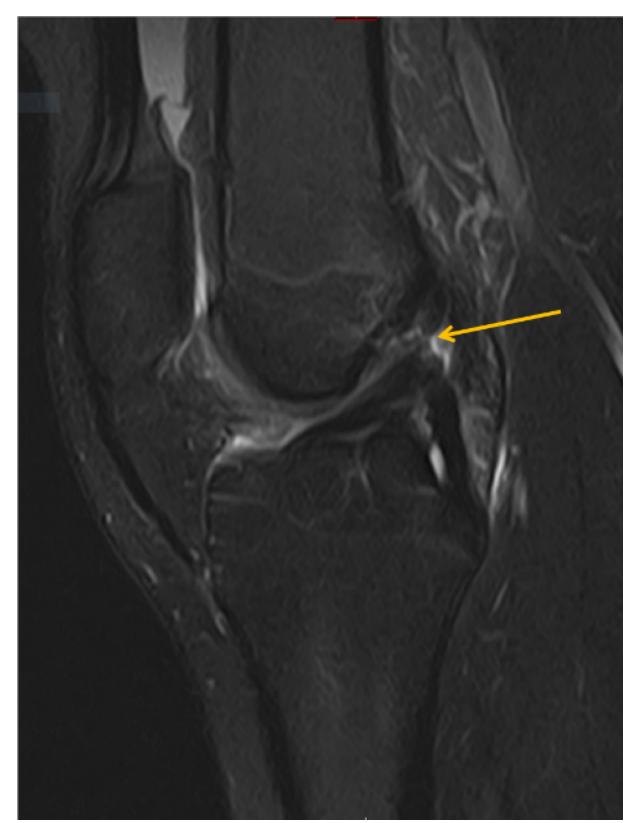

Figure 1. Sagittal T2 weighted MR image after the patient's initial injury demonstrating a proximal avulsion of the ACL, as indicated by the arrow

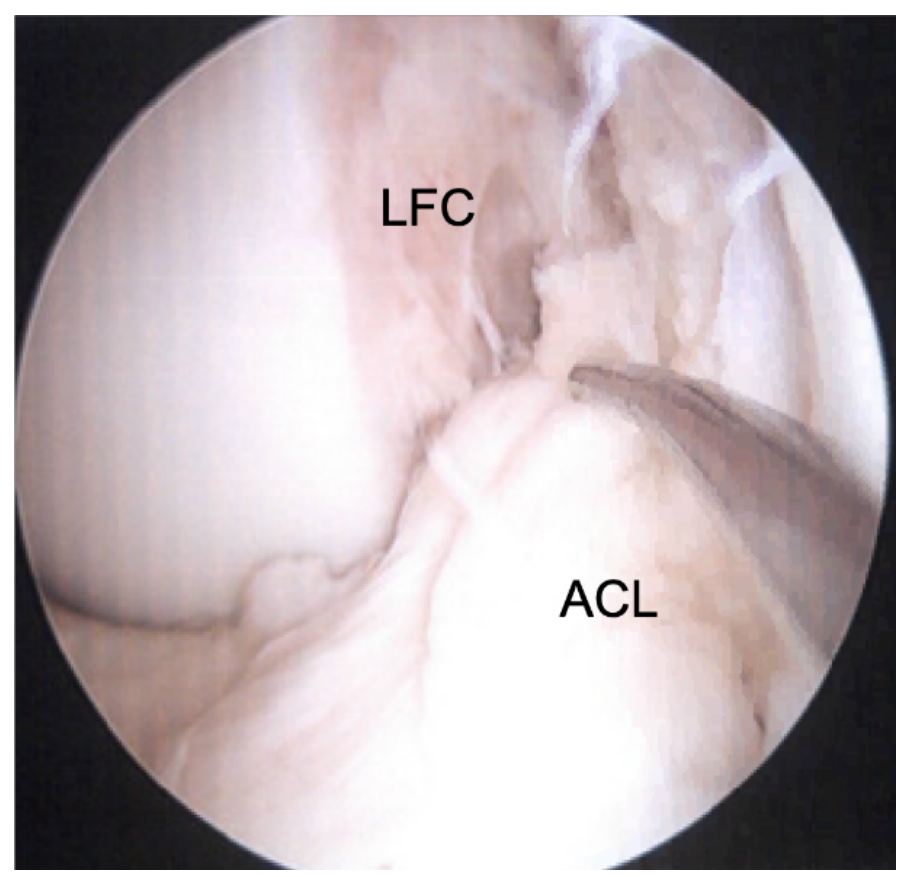

Figure 2. Arthroscopic view from the anterolateral portal viewing into the notch, demonstrating the avulsion of the ACL from the femoral footprint on the lateral femoral condyle. The probe is demonstrating the ligament displacement from its femoral insertion. $(\mathrm{ACL}=$ anterior cruciate ligament; $\mathrm{LFC}=$ lateral femoral condyle $)$

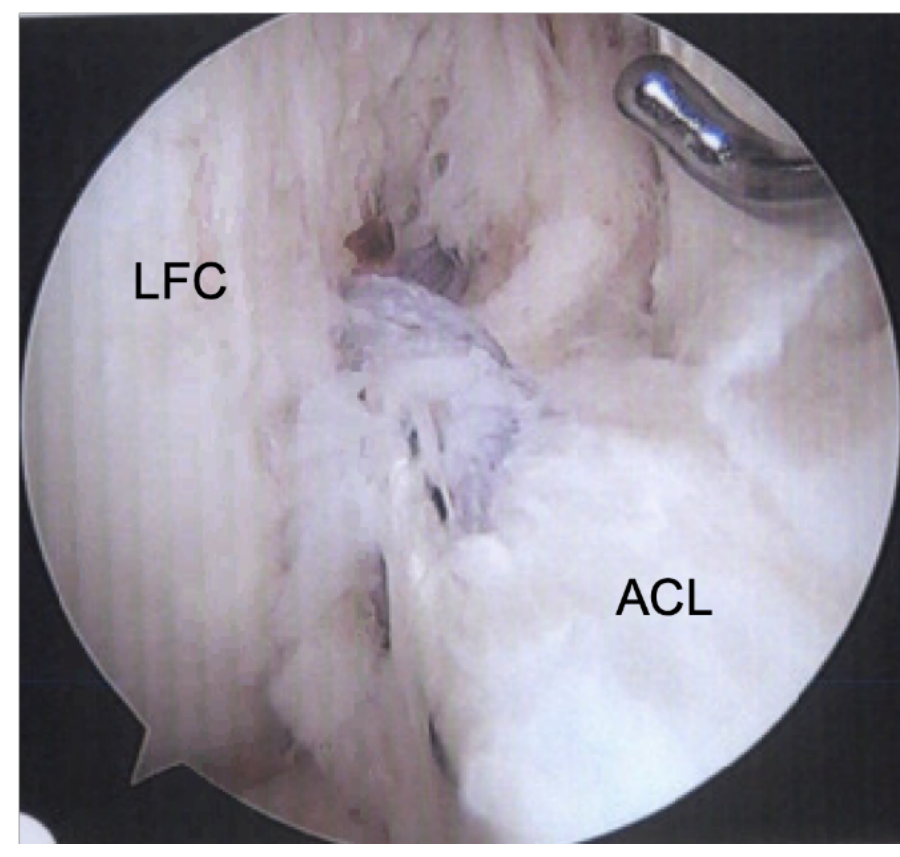

Figure 3. Arthroscopic view from the anterolateral portal viewing into the notch, demonstrating primary repair of the ACL back to the femoral footprint. $(\mathrm{ACL}=$ anterior cruciate ligament; LFC = lateral femoral condyle)

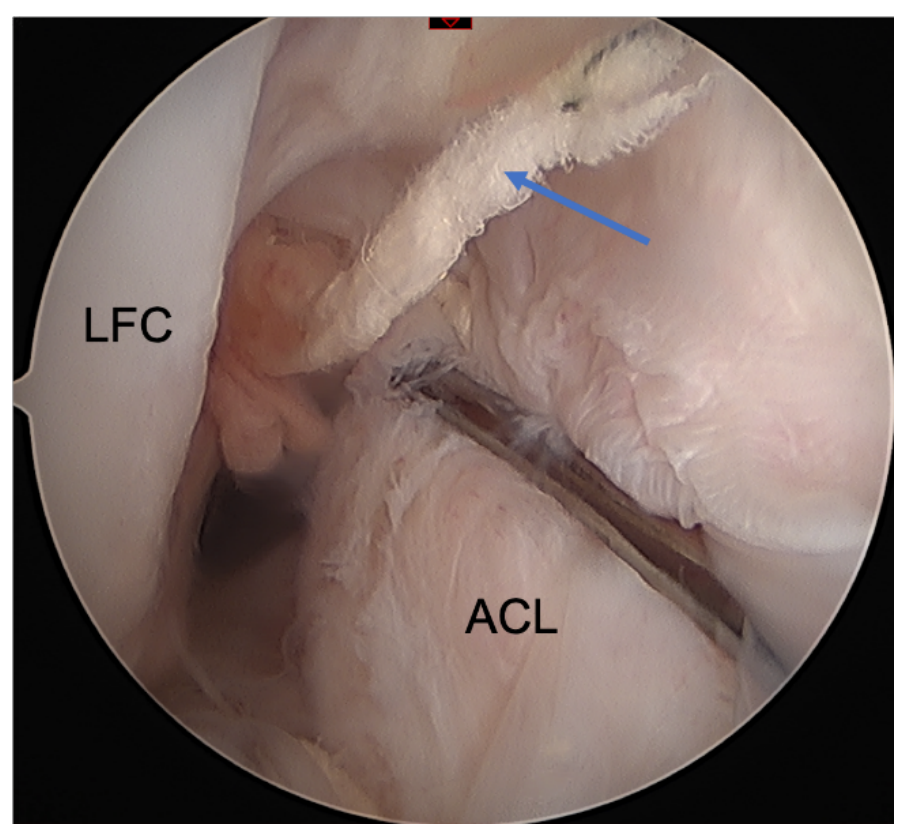

Figure 4. Arthroscopic view from the anterolateral portal demonstrating a re-tear of the ACL from its femoral footprint. There is suture remnant present from the prior repair, indicated with a blue arrow. (ACL $=$ anterior cruciate ligament; $\mathrm{LFC}=$ lateral femoral condyle)

\section{Discussion}

ACL repair has several proposed advantages when compared to reconstruction, including eliminating donor site morbidity and preserving native biomechanics and proprioception. Our enhanced understanding of the vascularity and healing potential of different segments of the ACL has propelled primary repair of type 1 proximal avulsions to be a viable option to restore stability to an acutely ACLdeficient knee6,12. 
A meta-analysis of recent literature on primary repair of proximal ACL tears reported a failure rate of $11 \%$ in 1,101 patients with a mean follow-up of 2.1 years [8]. Additionally, side-to-side KT-1000 testing revealed differences of $<3 \mathrm{~mm}$ in $77 \%$ of patients. Jonkergouw, et al. reported results of 56 patients who underwent primary ACL repair with a failure rate of $10.7 \%$ at a mean 3.2-year follow-up [13]. DiFelice, et al. followed 11 patients for a mean of 6 years and reported a $9 \%$ failure rate, with $87.5 \%$ of patients having a difference of $<3 \mathrm{~mm}$ on side-to-side KT-1000 measurements [14]. However, another study with a mean 6.6year follow-up reported failure rates of $25 \%$ [15]. Although techniques for repair continue to improve, outcomes must be contextualized to the gold standard-ACL reconstruction-which has a failure rate of $2-6 \%$ at 5 years [16-17].

The above studies and the majority of clinical ACL repair studies are conducted in adult patients. Outcomes of repair in pediatric and adolescent patients have not been thoroughly researched, but the limited literature is conflicting. Dabis, et al. reported a $0 \%$ failure rate at 2-year follow-up in their cohort of 20 pediatric patients treated with primary repair [18]. However, in a 3-year cohort study of adolescent patients by Gagliardi, et al. comparing 22 patients who underwent ACL repair to 157 patient who underwent reconstruction, the failure rate in the repair group was $48 \%, 10.66$ times higher than the reconstruction group [19]. Importantly, these studies were both short-term follow-up, with relatively low subject numbers.

Despite the proposed advantages of proximal ACL repair and positive short and mid-term outcomes of recent studies, the 17-yearold female patient presented in this case returned over three years later with a failed ACL repair that required reconstruction. Even with careful patient selection, utilization of an established surgical technique, and reassuring post-operative benchmarks, an acceptable outcome was not achieved. Further research on long-term outcomes of proximal avulsion ACL repair, particularly in young, active patients, is necessary to guide surgeon decision-making.

\section{References}

1. Warren RF (1983) Primary repair of the anterior cruciate ligament. Clin Orthop 172: $65-70$.

2. Feagin JA, Curl WW (2016) Isolated tear of the anterior cruciate ligament: 5-year follow-up study: Am J Sports Med 4: 95-100. [Crossref]

3. Taylor SA, Khair MM, Roberts TR, DiFelice GS (2015) Primary Repair of the Anterior Cruciate Ligament: A Systematic Review. Arthroscopy 31: 2233-2247. [Crossref]

4. Nogalski MP, Bach BR (1993) A review of early anterior cruciate ligament surgical repair or reconstruction. Results and caveats. Orthop Rev 22: 1213-1223. [Crossref]
5. Engebretsen L, Svenningsen S, Benum P (1988) Poor results of anterior cruciate ligament repair in adolescence. Acta Orthop Scand 59: 684-686. [Crossref]

6. Sherman MF, Lieber L, Bonamo JR, Podesta L, Reiter I (1991) The long-term followup of primary anterior cruciate ligament repair: Defining a rationale for augmentation. $\mathrm{Am}$ J Sports Med 19: 243-255. [Crossref]

7. DiFelice GS, Villegas C, Taylor S (2015) Anterior Cruciate Ligament Preservation Early Results of a Novel Arthroscopic Technique for Suture Anchor Primary Anterior Cruciate Ligament Repair. Arthroscopy 31: 2162-2171. [Crossref]

8. van der List JP, Vermeijden HD, Sierevelt IN, DiFelice GS, van Noort A, et al. (2020) Arthroscopic primary repair of proximal anterior cruciate ligament tears seems safe but higher level of evidence is needed: a systematic review and meta-analysis of recent literature. Knee Surg Sports Traumatol Arthrosc 28: 1946-1957. [Crossref]

9. Murray MM, Magarian E, Zurakowski D, Fleming BC (2010) Bone-to-Bone Fixation Enhances Functional Healing of the Porcine Anterior Cruciate Ligament Using a Collagen-Platelet Composite. Arthroscopy 26: S49-S57. [Crossref]

10. Fleming BC, Spindler KP, Palmer MP, Magarian EM, Murray MM (2009) Collagenplatelet composites improve the biomechanical properties of healing anterior cruciate ligament grafts in a porcine model. Am J Sports Med 37: 1554-1563. [Crossref]

11. Nwachukwu BU, Patel BH, Lu Y, Allen AA, Williams RJ (2019) Anterior Cruciate Ligament Repair Outcomes: An Updated Systematic Review of Recent Literature. Arthroscopy 35: 2233-2247. [Crossref]

12. Nguyen DT, Ramwadhdoebe TH, Hart CP van der, Blankevoort L, Tak PP, et al. (2014) Intrinsic healing response of the human anterior cruciate ligament: A histological study of reattached ACL remnants. J Orthop Res 32: 296-301. [Crossref]

13. Jonkergouw A, van der List JP, DiFelice GS (2019) Arthroscopic primary repair of proximal anterior cruciate ligament tears: outcomes of the first 56 consecutive patients and the role of additional internal bracing. Knee Surg Sports Traumatol Arthrosc 27: 21-28. [Crossref]

14. DiFelice GS, van der List JP (2018) Clinical Outcomes of Arthroscopic Primary Repair of Proximal Anterior Cruciate Ligament Tears Are Maintained at Mid-term Follow-up. Arthroscopy 34: 1085-1093. [Crossref]

15. Hoffmann C, Friederichs J, von Rüden C, Schaller C, Bühren V, et al. (2017) Primary single suture anchor re-fixation of anterior cruciate ligament proximal avulsion tears leads to good functional mid-term results: a preliminary study in 12 patients. J Orthop Surg Res 12: 171. [Crossref]

16. Kaeding CC, Pedroza AD, Reinke EK, Huston LJ, Spindler KP (2015) Risk Factors and Predictors of Subsequent ACL Injury in Either Knee After ACL Reconstruction: Prospective Analysis of 2488 Primary ACL Reconstructions From the MOON Cohort. Am J Sports Med 43: 1583-1590. [Crossref]

17. Yunes M, Richmond JC, Engels EA, Pincweski LA (2001) Patellar versus hamstring tendons in anterior cruciate ligament reconstruction: A meta-analysis. Arthroscopy 17: 248-257. [Crossref]

18. Dabis J, Yasen SK, Foster AJ, Pace JL, Wilson AJ (2020) Paediatric proximal ACL tears managed with direct ACL repair is safe, effective and has excellent short-term outcomes. Knee Surg Sports Traumatol Arthrosc 28: 2551-2556. [Crossref]

19. Gagliardi AG, Carry PM, Parikh HB, Traver JL, Howell DR, et al. (2019) ACL Repair With Suture Ligament Augmentation Is Associated With a High Failure Rate Among Adolescent Patients. Am J Sports Med 47: 560-566. [Crossref]

Copyright: (C2020 Quinn CA. This is an open-access article distributed under the terms of the Creative Commons Attribution License, which permits unrestricted use, distribution, and reproduction in any medium, provided the original author and source are credited. 